\title{
Genetic heterozygosity and reproductive success in the green treefrog, Hyla cinerea
}

\author{
SUSAN MCALPINE \\ University of Georgia's Savannah River Ecology Laboratory, P.O. Drawer E, Aiken, SC 29802, U.S.A.
}

\begin{abstract}
The relationship between genetic variation and fitness characteristics is important because reduced variation at the population level is usually associated with reduced viability of individuals. Adult green treefrogs from a single population were examined at eight polymorphic allozyme loci to test the prediction that a positive correlation exists between reproductive success and number of heterozygous loci. In females, clutch size, corrected for snout-vent length, and total number of surviving offspring were significantly correlated with number of heterozygous loci. The relationship with percentage hatched showed the same correlation, but it was not significant. Body size as measured by snout-vent length was not associated with number of heterozygous loci, although larger females had significantly more hatched offspring. In males, heterozygosity was not associated with body size or hatching success of the clutch. Total reproductive success in females was positively correlated with number of heterozygous loci, while factors such as body size, which may affect fitness, were not.
\end{abstract}

Keywords: heterozygosity, Hyla cinerea, Hylidae, life history, reproductive success.

\section{Introduction}

Recent evidence from natural populations indicates that more heterozygous individuals have characteristics which result in enhanced fitness compared with more homozygous individuals (Allendorf \& Leary, 1986; Zouros \& Foltz, 1987). Greater metabolic efficiency of heterozygotes relative to homozygotes may account for the enhanced fitness correlates. More heterozygous old-field mice (Peromyscus polionotus) maintained their weight better than more homozygous mice when fed a low-quality diet, but no differences were detected when the mice were fed a high-quality diet (Teska et al., 1990). In the tiger salamander (Ambystoma tigrinum), more heterozygous animals consume less oxygen at rest and more during forced vigorous exercise than more homozygous ones (Mitton et al., 1986). Koehn \& Gaffney (1984) found a positive correlation between multi-locus heterozygosity and growth rate at an early age in blue mussels (Mytilus edulis), but this relationship became weaker as the animals aged. As gamete production became greater than somatic tissue production, a positive association with amount of gametic tissue was found (Rodhouse $e t$ al., 1986). The shift apparently resulted from a change in allocation of energy at older ages. The energy beyond that required for maintenance may be used for continued growth, increased body condition (e.g. fat reserves), or reproduction.

A positive association between body size and multilocus heterozygosity has been found in invertebrates and all classes of vertebrates (Zorous \& Foltz, 1987). The larger body size may partially be attributed to the increased metabolic efficiency of heterozygotes. Individuals which grow faster have a lower cumulative risk of predation, since they escape from size-selective predators at an earlier age than the more slowly growing individuals; thus, they increase their chances of living to reproduce.

Male body size is a predictor of breeding success in some species, since males spend a great deal of energy attracting and guarding females or possibly rearing the young. Large body size is also advantageous in females; larger females anurans produce larger clutches (Salthe \& Duellman, 1973). Crump (1984) has documented that larger eggs result in larger hatchlings, and there is evidence that more heterozygous female fish have larger eggs (Danzmann et al., 1988). There are advantages to being physically large and to producing large offspring in some environments; however, there is a trade-off between number and size of offspring, and maximization of surviving offspring is most important. 
The relationships among heterozygosity, energy availability, body size, and reproductive success should be examined in natural populations.

The primary objective of the author was to test the prediction that there is a positive correlation between number of heterozygous loci and reproductive success in the green treefrog, Hyla cinerea. Reproductive success in females is assessed by clutch size, percentage of clutch hatched, number of hatched offspring (clutch size $\times$ percentage hatched $)$, and body size as measured by snout-vent length and in males by percentage of clutch hatched, body size, and mating success. Whether the number of hatched offspring of females was the result of a larger clutch or greater hatching success or both was under investigation. Amplexed males were expected to be heterozygous at more loci and have greater body size than calling males which were not in amplexus.

The green treefrog is ideal for studying the relationships between genetic heterozygosity and fitness correlates. It is abundant, and both parents are easily captured while in amplexus. Larger males are more likely to call and therefore mate than are smaller males, and clutch size varies among females (Garton \& Brandon, 1975). Also, green treefrogs have a relatively high level of genetic variation as assessed by average individual heterozygosity $(0.122 \pm 0.015,2$ S.E.; Etges, 1979).

\section{Materials and methods}

Adult treefrogs were hand-collected from the vegetation near the shoreline of a permanent pond during June-August, 1989. The study site, Fire Pond, is a manmade pond on the U.S. Department of Energy's Savannah River Site located in Aiken and Barnwell Counties, South Carolina, U.S.A. Eighty-two amplectant pairs and 84 calling males were captured. Snout-vent length, a measure of body size, of each frog was taken to the nearest $0.01 \mathrm{~mm}$, and pairs were placed in buckets in the laboratory and allowed to spawn overnight.

Percentage hatched, a measure of egg viability, was determined for each clutch. Nine groups of 20 eggs from each clutch were placed randomly in pans containing well water and hatched in the laboratory. The eggs were monitored at 8-h intervals, and those showing signs of fungal infection or not developing were removed. Clutches were photographed and counted to determine total clutch size.

Horizontal starch gel electrophoresis was used to estimate the level of heterozygosity for each individual. Liver and muscle tissue were ground with an equal portion of buffer $(0.60 \mathrm{~g}$ Tris, $42.8 \mathrm{~g}$ sucrose, $0.45 \mathrm{~g}$ dithiothreitol, and water to equal $500 \mathrm{ml}$ ) and centrifuged for approximately $30 \mathrm{~s}$. This population was examined for variation at 21 presumptive loci, and polymorphisms were consistently resolvable at eight loci. The protein systems and buffer types used were: aspartate aminotransferase (AAT-2; 2.6.1.1), and aconitate hydratase (AH-1, AH-2; 4.2.1.3) on tris-

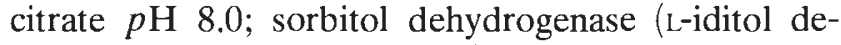
hydrogenase, SORDH; 1.1.1.14) on poulik discontinuous Tris-citrate (Selander et al., 1971); and isocitrate dehydrogenase (IDHP-2; 1.1.1.42), malate dehydrogenase (MDH-1, MDH-2; 1.1.1.37), and phosphoglucomutase (PGM-2; 5.4.2.2) on Tris-EDTA citrate $p \mathrm{H} 7.1$ (Ayala et al., 1972). Stains follow Gerhardt et al. (1980) and McAlpine (1992).

The two fastest allozymes of AH-2 had very similar mobilities and could not be separated consistently. Alternate buffer types and grouping like-genotypes in adjacent slots of re-run gels did not help resolve these phenotypes. Therefore, the two fastest alleles were synonomyzed, and this locus was scored as if there were three alleles. Thus, the number of heterozygous loci is probably slightly underestimated.

A one-way analysis of variance (ANOVA) was used to look at the association of four variables with the number of heterozygous loci: body size, clutch size, percentage hatched, and number of hatched offspring (clutch size $\times$ percentage hatched). Percentage of the variance explained by number of heterozygous loci was determined using a variance component analysis (SAS procedure VARCOMP, default method). This allows the percentage of the variance explained by the model to be compared with other studies, whereas use of the variance ratio from the sums of squares of the ANOVA would not allow comparisons across studies.

Hatching success was evaluated for both the male and female parent. Body size was treated as a covariate, and least-squared means were used to remove the effect of body size on clutch size and number of hatched offspring. A regression of hatched offspring on body size was conducted to determine whether larger females had more offspring. In addition, the effects of time of season (early, middle, or late) and clutch size on percentage hatched were evaluated. All means are reported with one standard error.

Statistical analyses of the data were performed using the Statistical Analysis Systems (SAS Institute, 1985). All pairwise combinations of loci were analysed for linkage disequilibrium using the program LINKDIS (Hill, 1974).

\section{Results}

The mean, standard error, and range of clutch size, percentage hatched, number of hatched offspring, and 
Table 1 Mean, standard error, and range for measures of reproductive success in amplectant and calling male green treefrogs captured from a single pond. Number of hatched offspring $=$ clutch size $\times$ percentage of clutch hatched

\begin{tabular}{lcl}
\hline $\begin{array}{l}\text { Measure of } \\
\text { reproductive success }\end{array}$ & Mean (1 S.E.) & Range \\
\hline Clutch size & $1472(51)$ & $288-2903$ \\
Percentage hatched & $87.3(1.2)$ & $32.8-100$ \\
No. hatched offspring & $1256(57)$ & $177-2441$ \\
Body size (mm) & & \\
$\quad$ Calling males & $51.72(0.37)$ & $44.11-59.79$ \\
$\quad \begin{array}{l}\text { Mated females } \\
\text { Mated males }\end{array}$ & $53.09(0.41)$ & $43.01-62.51$ \\
& $51.89(0.32)$ & $44.05-57.72$ \\
\hline
\end{tabular}

body size are summarized in Table 1 . Body size was similar among groups. As expected, clutch size was strongly affected by body size, and female body size was a good indicator of number of offspring but explained little of the variance $\left(r^{2}=0.11\right)$. Neither seasonal period nor clutch size significantly affected percentage hatched.

Mean multilocus heterozygosity was $0.104 \pm 0.018$ for all individuals and was similar among groups. In calling males, heterozygosity was $0.095 \pm 0.021$, in females $0.105 \pm 0.015$, and in mated males $0.110 \pm 0.021$. Sample sizes ranged from 80 to 82 individuals per group. The number of loci at which an individual was heterozygous ranged from 0 to 6 . Only 10 individuals were variable at more than four loci; thus, data from individuals variable at $\geq 4$ loci were grouped. Sample sizes for each number of heterozygous loci ranged from 5 to 29 for calling males, 6 to 25 for females, and 2 to 27 for mated males.

Clutch size and number of hatched offspring were significantly correlated with number of heterozygous loci $(P<0.05)$. No single locus was of particular significance in either of these relationships. In each case, individuals that were heterozygous at two and three loci had the largest values (Fig. 1). Hatching success of females showed a similar pattern but was not significant. Mean female body size was not related to the number of heterozygous loci. A regression of clutch size on body size for females differing in number of heterozygous loci showed that clutch size varied more among number of heterozygous loci at smaller body sizes than at larger sizes although the differences were not significant.

In males, the number of heterozygous loci was not associated with any measure of reproductive success. Mated and calling males and similar numbers of heterozygous loci. Also, neither hatching success of the clutch spawned by the amplectant female nor mean
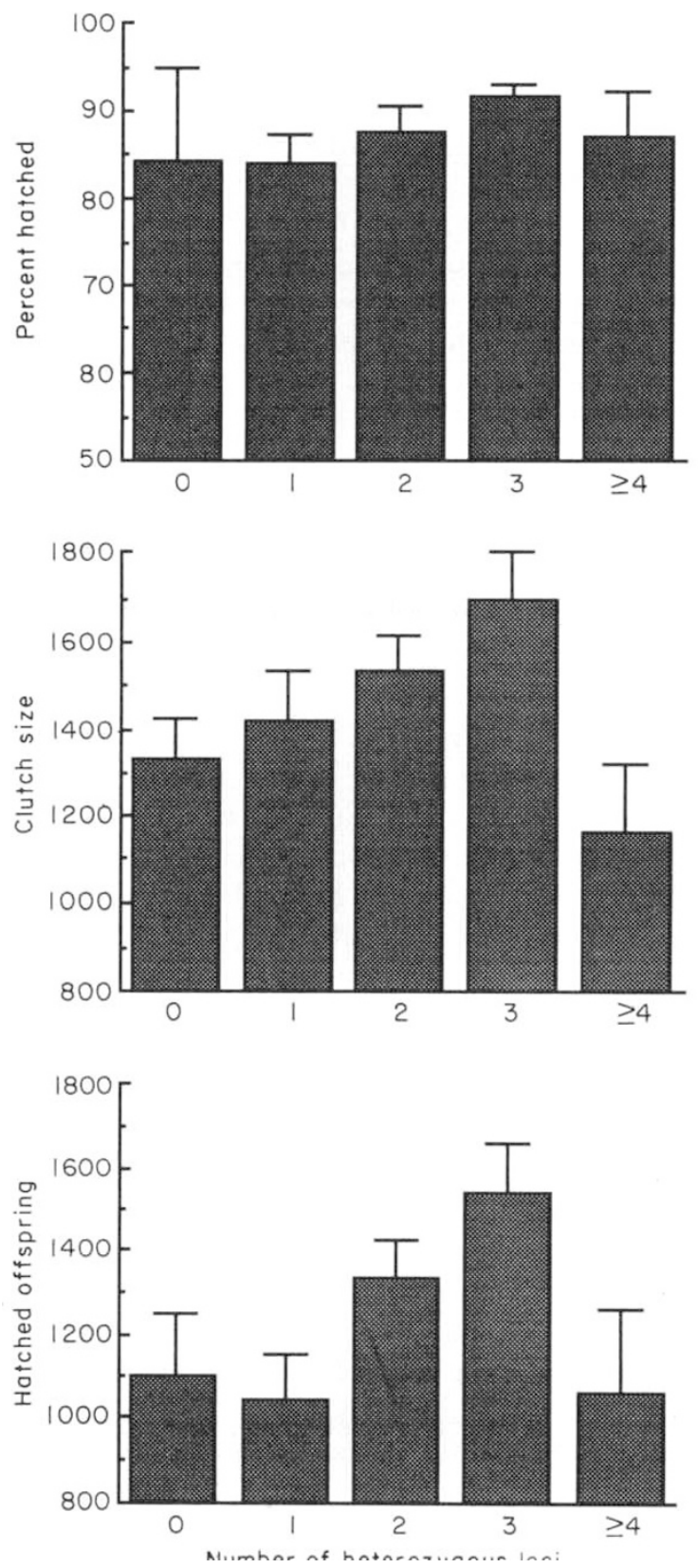

Fig. 1 Mean and one standard error for percentage of clutch hatched, clutch size, and number of hatched offspring (percentage hatched $\times$ clutch size) of Hyla cinerea females differing in number of heterozygous loci. Clutch size and number of hatched offspring were corrected for snout-vent length. Differences among individuals with various number of heterozygous loci are indicated by probability values: percentage hatched, not significant; clutch size, $P<0.05$; number of hatched offspring, $P<0.05$.

male body size was related to number of heterozygous loci.

Number of heterozygous loci explained 2.8 per cent and 0.9 per cent of the variance in percent hatched in 
males and females, respectively, 2.5 per cent of the variance in clutch size, and 6.1 per cent in the number of offspring. The variance explained in body size ranged from 0.1 per cent in calling males to 2.1 per cent in mated males.

There is no evidence of linkage disequilibrium among the loci examined in this study. This result is consistent with other data on conserved linkage associations in vertebrate species (Morizot \& Siciliano, 1984).

\section{Discussion}

Hatching success ranged widely, but most clutches were within a relatively small range. Clutch size and, therefore, number of hatched offspring varied widely among females. The mean clutch size (1472 eggs) found in this study was much larger than noted previously. Garton \& Brandon (1975) reported five females in southern Illinois that averaged 700 eggs per clutch. There was very little variance in body size in this population; all groups had similar mean size.

Females that were either larger or heterozygous at more loci had more hatched offspring. Thus, the predicted result, more heterozygous females having more offspring, was seen but the mechanism was different than expected. Individuals with a greater number of heterozygous loci were expected to have greater body size and therefore more offspring, but body size was not associated with heterozygosity. Larger females had larger clutches, and since hatching success did not vary, larger females had more hatched offspring. In addition, more heterozygous females had more hatched offspring regardless of body size (Fig. 1). This result was due to an association between heterozygosity and clutch size rather than with body size.

A positive correlation between body size and multilocus heterozygosity has been found in rainbow trout (Salmo gairdneri; Danzmann et al., 1988), mosquitofish (Gambusia holbrooki; Smith et al., 1989), tiger salamanders (Pierce \& Mitton, 1982), and white-tailed deer (Odocoileus virginianus; Chesser \& Smith, 1987). The variance in body size was very small in this population of treefrogs $(52.23 \pm 0.22 \mathrm{~mm})$; thus, there may have been so little variance to partition that no relationship was found. A positive correlation also has been found between percentage hatched and heterozygosity at certain loci in females of other species. For example, Frelinger (1972) showed that the hatching success of eggs laid by pigeons which were heterozygous at the transferrin locus was 40 per cent higher than that of eggs laid by those homozygous at that locus. Two factors may have contributed to the lack of correlation seen here. There was very little variance in percentage hatched for all levels of heterozygosity $(87.3 \pm 1.2$ per cent $)$, and most of that variance was among individuals with no heterozygous loci $(84.5 \pm 10.4$ per cent; Fig. 1$)$. The large standard error resulted from one female that had low hatching success (32.8 per cent) and a small sample size of six individuals.

The trend between clutch size and hatched offspring and number of heterozygous loci was not linear but hyperbolic. Individuals with intermediate amounts of heterozygosity had larger clutches and more hatched offspring. Chesser \& Smith (1987) found a similar relationship in white-tailed deer. Females heterozygous at two, three, and four loci had a significantly greater number of fetuses than those which had either more or fewer heterozygous loci. A similar relationship was also found in body size of adult female mosquitofish with individuals heterozygous at two and three loci having the greatest mean standard lengths (Smith et al., 1989). This relationship could be due to a carry-over maternal effect, but this is unlikely since the maternal benefits seen early in the larval period of amphibians were no longer present at metamorphosis (Crump, 1984; Semlitsch \& Gibbons, 1990). Also, there may be an optimal amount of variability with the most and least heterozygous individuals having reduced fitness correlates.

Male mating success was expected to be associated positively with body size and body size with number of heterozygous loci; however, there was no association between mating success, body size, or number of heterozygous loci. Mated and calling males were similar in body size and number of heterozygous loci. Enhanced mating success has been associated with heterozygosity in other studies. Watt et al. (1983) found that male Colias butterflies that were heterozygous at two loci, phosphoglucose isomerase (PGI) and phosphoglucomutase, mated more often than expected by chance. Based on known functional differences from in vitro biochemical studies on PGI (Watt, 1983), the functional effects of the alleles supported the predictions. In the green treefrog, McAlpine (1992) found that significantly more mated males were heterozygous at the isocitrate dehydrogenase- 2 locus than were calling males. Two factors may have contributed to the lack of association found for males in this study. First, mated and calling males are not mutually exclusive. The number of males that can breed on a given night is limited by the number of gravid females in the population on the night (Gerhardt et al., 1987). Alpha males may not mate on a night with few females in the population, whereas on another night, secondary males may mate after the choice males have amplexed. Secondly, the variance in body size between mated and calling 
males was very small. As with females, there may have been so little variance to partition that no relationship was found.

While factors such as body size which may affect fitness were not correlated to number of heterozygous loci in this population, reproductive success of females was. Females which were heterozygous at more loci had larger clutches and a larger number of hatched offspring. Those with greater body size also were associated with larger clutches and more offspring but not with heterozygosity. Thus, heterozygosity may influence reproductive success but through a mechanism other than increased body size. These results expand our understanding of the association between heterozygosity and its relationship with various fitness correlates by illuminating possible changes in the routes of energy allocation.

\section{Acknowledgements}

I wish to thank the many friends and colleagues who assisted with the field collections, especially C. McCreedy. P. Dixon provided statistical help. Earlier drafts of this manuscript were strengthened by comments from M. H. Smith, W. Gibbons, J. Hamrick, J. Laerm, M. Mulvey and R. Warren. This research was supported by contract DE-AC09-76SR00819 between the U.S. Department of Energy and the University of Georgia's Savannah River Ecology Laboratory.

\section{References}

ALLENDORF, F. A. AND LEARY, R. F. 1986. Heterozygosity and fitness in natural populations of animals. In: Soule, M. E. (ed.) Conservation Biology: The Science of Scarcity and Diversity, Sinauer and Assoc., Sunderland, MA, pp. 57-76.

AYAlA, F. J., POWELL, J. R., TRACEY, M. C., MOURAO, C. A. AND PEREZ, s. 1972. Enzyme variability in the Drosophila willistoni group. IV. Genetic variation in natural populations of Drosophila willistoni. Genetics, 70, 113-139.

CHESSER, R. K. AND SMITH, M. H. 1987. Relationships of genetic variation on growth and reproduction in white-tailed deer. In: Wemmer, C. M. (ed.) Biology and Management of the Cervidae, Smithsonian Inst. Press, Washington, DC, pp. $168-177$.

CRUMP, M. L. 1984. Intraclutch egg size variability in Hyla crucifer (Anura: Hylidae). Copeia, 302-308.

DANZMANN, R. G., FERGUSON, M. M. AND ALLENDORF, F. W. 1988. Heterozygosity and components of fitness in a strain of rainbow trout. Biol. J. of the Linn. Soc., 33, 285-304.

ETGES, W. J. 1979. Ecological genetic relationships in selected anurans of the southeastern United States, Master's Thesis, University of Georgia.

FRELINGER, J. A. 1972. The maintenance of transferrin polymorphism in pigeons. Proc. Nat. Acad. Sci. U.S.A., 69, 326-329.
GARTON, J. S. AND BRANDON, R. A. 1975. Reproductive ecology of the green treefrog, Hyla cinerea, in southern Illinois (Anura: Hylidae). Herpet., 31, 150-161.

GERHARDT, H. C., DANIEL, R. E., PERRILL, S. A. AND SCHRAM, S. 1987. Mating behavior and male mating success in the green treefrog. Anim. Behav., 35, 1490-1503.

GERHARDT, H. C., GUTTMAN, S. I. AND KARLIN, A. A. 1980. Natural hybrids between Hyla cinerea and Hyla gratiosa: morphology, vocalization and electrophoretic analysis. Copeia, 1980, $577-584$.

HILL, w. G. 1974. Estimation of linkage disequilibrium in a randomly mating population. Heredity, 33, 229-239.

KOEHN, R. K. AND GAFFNEY, P. M. 1984. Genetic heterozygosity and growth rate in Mytilus edulis. Mar. Biol., 82, 1-7.

MCALPINE, S. 1992. Genetic correlates of fitness in the green treefrog, Hyla cinerea. Ph.D Thesis, University of Georgia.

MITTON, J. B., CAREY, C. AND KOCHER, T. D.1986. The relation of enzyme heterozygosity to standard and active oxygen consumption and body size of tiger salamanders, Ambystoma tigrinum. Physiol. Zool., 59, 574-582.

MORIZOT, D. C. AND SICILIANO, M. J. 1984. Gene mapping in fishes and other vertebrates. In: Turner, B. J. (ed.) Evolutionary Genetics of Fishes, Plenum Press, New York, pp. 173-234.

PIERCE, B. A. AND mITTON, J. B. 1982. Allozyme heterozygosity and growth in the tiger salamander, Ambystoma tigrinum. J. Heredit., 73, 250-253.

RODHOUSE, P. G., MCDONALD. J. H. NEWELL, R. I. E. AND KOEHN, R. K. 1986. Gamete production, somatic growth and multiplelocus enzyme heterozygosity in Mytilus edulis. Mar. Biol., 90, 209-214.

SAlthe, s. N. AND DUEllman, w. E. 1973. Quantitative constraints associated with reproductive mode in anurans. In: Vial, J. L. (ed.) Evolutionary Biology of the Anurans: Contemporary Research on Major Problems, University of Missouri Press, Columbia, MO, pp. 229-249.

SAS INSTITUTE INC. 1985. SAS User's Guide: Statistics. Version 5. SAS Institute Inc., Cary, North Carolina.

SELANDER, R. K., SMITH, M. H., YANG, S. Y., JOHNSON, W. E. AND GENTRY, J. B. 1971. Biochemical polymorphism and systematics in the genus Peromyscus. I. Variation in the old-field mouse (Peromyscus polionotus). Studies in Genetics IV. University of Texas Publ., 7103, 49-90.

SEMLITSCH, R. D. AND GiBbONS, J. w. 1990. Effects of egg size on success of larval salamanders in complex aquatic environments. Ecology, 71, 1789-1795.

SMITH, M. H., SCRIBNER, K. T., HERNANDEZ, J. D. AND WOOTEN, M. C. 1989. Demographic, spatial, and temporal genetic variation in Gambusia. In: Meffe, G. K., and Snelson, F. F. (eds) Ecology and Evolution of Live Bearing Fishes (Poeciliidae), Prentice Hall, Englewood Cliffs, New Jersey, pp. 235-257.

TESKA, W. R., SMITH, M. H. AND NOVAK, J. M. 1990. Food quality, heterozygosity, and fitness correlates in Peromyscus polionotus. Evolution, 44, 1318-1325.

WATT, w. B. 1983. Adaptation at specific loci. II. Demographic and biochemical elements in the maintenance of the Colias PGI polymorphism. Genetics, 103, 691-724. 
WATT, W. B., CASSIN, R. C. AND SWAN, M. S. 1983. Adaptation at specific loci. III. Field behavior and survivorship differences among Colias PGI genotypes are predictable from in vitro biochemistry. Genetics, 103, 725-739.
ZOUROS, E. AND FOLTZ, D. W. 1987. The use of allelic isozyme variation for the study of heterosis. In: Rattazzi, M. C., Scandalios, J. G. and Whitt, G. S. (eds) Isozymes: Current Topics in Biological and Medical Research, vol. 13, A. R. Liss, New York, pp. 1-59. 